research activities were supported by a contract from the Atomic Energy Commission. From 1958 until 1960 he worked as a research associate at the Massachusetts Institute of Technology. Born in Rochester, New York, Dr. Freeman completed his B.S. in chemistry at the University of Rochester in 1952; he then went to the Carnegie Institute of Technology for his M.S. in 1954, and gained his Ph.D. at the Massachusetts Institute of Technology in 1957. His professional affliations include membership in Phi Lambda Upsilon (president of the Massachusetts Institute of Technology Chapter in 19581959), American Chemical Society, American Institute of Physics, American Optical Society, American Association for the Advancement of Science, and Sigma Xi.

\section{Preserving the Lake District}

Some of the points raised in the Report and Newsletter, September 1965, of the Friends of the Lake District are noted elsewhere in discussing the "Countryside in 1970" Conference (see pp. 1241, 1265 of this issue of Nature). It is obvious from the report, however, that the Friends of the Lake District are concerned that considerations of amenity are being pushed into a minor place in proposed amendments to the National Parks Act. They feel that without the expression of a widely based and well-informed body of public opinion the objects for which National Parks were created are unlikely to be achieved. Much of the criticism in this report centres on the water plans of Manchester, particularly the powers sought to construct a duplicate in Longsleddale of the Mardale tunnel, although it is recognized that the Order has been most carefully framed and that the initial quantities of water to be abstracted are so calculated that it is extremely difficult to estimate the effect on the two lakes. It is the ultimate effects and the immediate physical effects on Longsleddale that are the cause of misgivings, and the report does well to emphasize the viable alternative of extraction from rivers rather than lakes, and of the possibilities of desalination consideration of our water resources in terms of nineteenth-century thought is no longer valid. One welcome feature of the report is an indication of some improvement in the litter position, although constant effort and vigilance are still necessary.

\section{Information Activities of the U.S. National Academy of Sciences}

THE scientific information activities of the National Academy of Sciences-National Research Council of the United States are surveyed in a booklet recently issued by the Office of Documentation (National Academy of Sciences-National Research Council. Publication 1291: Scientific Information Activities of the National Academy of Sciences-National Research Council. A Report of the Office of Documentation. Revised 1965. Pp. 116. Washington, D.C.: National Academy of SciencesNational Research Council, 1965). This is a revision of a booklet issued under the same title in 1962. It covers such activities as the preparation of abstracting periodicals and literature digests, bibliographies, codes and classifications, tables of data, glossaries, handbooks, indexes, lists of publications, reviews, translations, the maintenance of information centres and the provision of information services, as well as studies and analyses in these fields. Original research publications are not included unless coneerned with these fields. The information is arranged alphabetically by the several divisions of: behavioural sciences; biology and agriculture; chemistry and chemical technology; earth sciences; engineering and industrial research; mathematics; and physical sciences. Within these are given, alphabetically by title, details of the committees, boards, offices or similar units.

\section{Scientists in the 'New Deal'}

THE summer issue of Minerva contains an interesting article by L. E. Auerbach, "Scientists in the New Deal", reviewing the relations between science and Government in the United States at the time of the formation of the Science Advisory Board. The article is essentially an account of the establishment and work of the Science Advisory Board under the National Research Council during its brief existence from July 1933 to December 1935. The Board sought to broaden the perspectives of the Government and to increase its awareness of foreign scientific achievements, but Mr. Auerbach considers that many of its recommendations were made largely in a political vacuum and that its attempt to formulate a comprehensive national science policy was essentially a failure, although the Board itself was rather a failure in adaptation to a new situation. This is attributed largely to conflict between the National Academy of Sciences and the Science Advisory Board. Dr. K. T. Compton held that if the National Academy of Sciences had been more involved with the social sciences, many of the difficulties would have been avoided. Mr. Auerbach also suggests that the Board would have been more influential if the scientific community as a whole had been able to agree on a united stand on the need for a national science policy. To-day its most valuable contribution to national welfare and towards raising the support and status of basic research appears to be the political experience it gave to men like $\mathbf{K}$. T. Compton, I. Bowman and Vannevar Bush.

\section{Science and Economic Growth}

AN article by Dr. C. E. Chastain, "Science, Tech. nology and Economic Growth", in Impact of Science on Society $(14$, No. 4; 1964) reviews some recent studies of the relation of science and technology to economic growth and emphasizes the need for further understanding of those relations, which require studying at three levels. We need to know more about the diffusion of technological knowledge for the development of now products and processes at the level of the individual firms in an industry. We need, next, a detailed study of some major industries, emphasizing the capacity of firms to adopt new technologies and analysing what motivates or hinders their advance. Thirdly, studies of the effect of technological change on the overall economy would also illustrate how technological change promotes new industries and new sectors in the economy. The Industrial Development Research Programme of the Institute of Science and Technology at the University of Michigan has recently completed an investigation, at the firm level, of engineering and technical developments and their business implications in the Michigan machine-tool industry, and a similar investigation of tho electronics industry will shortly be completed.

\section{The Royal Society of Edinburgh}

THE Year Book of the Royal Society of Edinburgh, 1965, covering the session 1963-64 (Pp. 133. Edinburgh: Royal Society of Edinburgh, 1965. 20s.; 3.50 dollars), contains the usual calendar, obituary notices, proceedings of the ordinary meetings and of the statutory general meeting, together with laws of the Society, accounts for the year ended July 21, 1964, and lists of Fellows of the Society, members of Council and recent awards. There are also lists of additions to the Library and of papers recently published in the Proceedings and Transactions of the Society. Among the obituary notices are those of W. M. Ames, Prof. R. N. Arnold, L. E. Bayliss, Prof. E. FinlayFreundlich, A. H. R. Goldie, Prof. I. A. Preece and Sir James Wallace Peck.

\section{The Manchester Literary and Philosophical Society}

THE Memoirs and Proceedings of the Manchester Literary and Philosophical Society (107; 1964-65. Pp. 142+lii. Manchester: Manchester Literary and Philosophical Society, 1965. 31s.6d.) includes, besides the account report of the Council, accounts, lists of presidents of the Society, 